Pediat. Res. 12: 665-668 (1978)

Familial hypobetalipoproteinemia

high density lipoprotein cholesterol

low density lipoprotein cholesterol

(C-HDL)

(C-LDL)

newborn

\title{
Neonatal Hypobetalipoproteinemia
}

\author{
CHARLES J. GLUECK, ${ }^{(19)}$ MARGOT J. MELLIES, REGINALD C. TSANG, PAULA M. STEINER, \\ AND EVAN A. STEIN \\ Departments of Medicine and Pediatrics, General Clinical Research Center, and Fels Division of Pediatric \\ Research, University of Cincinnati, Cincinnati, Ohio 45267
}

\section{Summary}

Quantitation of cord blood low density lipoprotein cholesterol (C-LDL), kindred studies, and longitudinal assessment allows the neonatal diagnosis of familial hypobetalipoproteinemia. To assess the relationship between neonatal hypobetalipoproteinemia and C-LDL in later infancy, kindred studies with follow-up were carried out in $\mathbf{1 1}$ families with a hypobetalipoproteinemic neonatal propositus, and in two families with normal neonates and hypobetalipoproteinemic adult propositi. Neonatal and familial hypobetalipoproteinemia was diagnosed in one kindred by quantitation of cord blood C-LDL, four-generation vertical transmission, and by demonstration of persistent hypobetalipoproteinemia in later infancy. In a second kindred, the neonate and her father, grandfather, and half-siblings had hypobetalipoproteinemia, but her C-LDL was normal $(96 \mathrm{mg} / \mathrm{dl})$ at age 6 months. Whether this unexpectedly normal C-LDL will persist, with a resultant "false positive" diagnosis at birth, can only be determined by longitudinal study. In a third kindred the hypobetalipoproteinemic neonate retained low C-LDL at age 2 years, the mother had borderline-low C-LDL levels, but there were no living siblings or maternal first degree relatives and familial hypobetalipoproteinemia could not be confirmed. The remaining eight hypobetalipoproteinemic neonates had normal C-LDL on follow-up examination; kindred studies failed to reveal familial hypobetalipoproteinemia. Two neonates with normal cord blood C-LDL, born to hypobetalipoproteinemic parents, retained normal $C$-LDL levels in infancy.

The recent evidence of the protective "anti-coronary risk" nature of low C-LDL (in familial hypobetalipoproteinemia) and elevated C-HDL (in familial hyperalphalipoproteinemia) has augmented interest in neonates having an exceptionally low value of C-LDL and a high value of high density lipoprotein cholesterol (C-HDL). Cord blood and kindred lipoprotein studies may identify families having heritable "anti-coronary risk" factors.

\section{Speculation}

Cord blood and kindred lipoprotein studies focused on the lower 2.5 th percentile for C-LDL may identify families having heritable "anti-coronary" risk factors.

Familial hypobetalipoproteinemia is characterized by sharply reduced levels of plasma total and C-LDL $(1-3,11)$. It rarely is accompanied by clinical symptoms or physical findings and is underdiagnosed and little recognized (2). Although there were only five well described kindreds as recently as 1972 (3), eight additional kindreds have been identified in Cincinnati population lipid and lipoprotein surveys (5). Kindreds with familial hypobetalipoproteinemia have prolonged life expectancy and reduced cardiovascular morbidity and mortality, putatively related to low levels of C-LDL, the primary atherogenic lipoprotein (5).
Most studies have focused on the upper 5th percentile of the C-LDL distribution and on familial hypercholesterolemia (9, $15,16)$, because of the acceleration of premature atherosclerosis in affected adults (14). The recent evidence of the protective "anti-coronary risk" nature of low C-LDL (in familial hypobetalipoproteinemia) and elevated C-HDL (in familial hyperalphalipoproteinemia) (5), has augmented interest in neonates having exceptionally low C-LDL and high C-HDL.

Quantitation of cord blood C-LDL, kindred studies, and longitudinal assessment allows the neonatal diagnosis of familial hypobetalipoproteinemia (8). Presumably, in a manner similar to neonatal hyperbetalipoproteinemia (15), a majority of hypobetalipoproteinemic neonates do not have "monogenic" hypobetalipoproteinemia. This study focused on the relationship between neonatal hypobetalipoproteinemia and C-LDL in later infancy, with emphasis on hypobetalipoproteinemia of a heritable or other unknown origin, in 11 families with a hypobetalipoproteinemic neonatal propositus, and in 2 families with normal neonates and hypobetalipoproteinemic adult propositi.

\section{MATERIALS AND METHODS}

\section{LIPID AND LIPOPROTEIN QUANTITATION}

Cord blood total cholesterol and C-LDL were quantitated in propositus neonates during a study of plasma lipids in 3000 unselected live births (16). Cord blood total, C-HDL, C-LDL, very low density lipoprotein cholesterol (C-VLDL), and triglyceride were determined as previously reported $(15,16)$.

The low 2.5 th percentile limits for cord blood total cholesterol and C-LDL were taken from 60 neonates whose parents had normal cholesterol and triglycerides (15). The distribution of CLDL in 117 unselected neonates (6) was also examined to provide comparison with that previously described in the 60 neonates (15).

Lipid and lipoprotein determinations in other kindred members were done following the Lipid Research Clinics Program methods $(10)$. For assessment of adult and other pediatric kindred members, upper normal limits of Fredrickson and Levy for cholesterol, triglyceride, and C-LDL were used (4). The triglyceride upper limits of Fredrickson and Levy (4) are probably too low, based on the preliminary experience of the Lipid Research Clinics Program, and all of the Fredrickson lipid and lipoprotein limits will probably be somewhat altered upon receipt of the final prevalence studies of the Lipid Research Clinics.

The 2.5th percentile for C-LDL in the 60 neonates (15) was $10 \mathrm{mg} / \mathrm{dl}$, and in our separate study of 117 neonates, $12 \mathrm{mg} / \mathrm{dl}$ (6). In Stein's study (13) of 494 unselected births, the 2.5th percentile for C-LDL was $14 \mathrm{mg} / \mathrm{dl}$, using comparable laboratory methods. The lower C-LDL limits in the study of Fredrickson et al. (4) for ages $0-19,20-29,30-39,40-49$, and 50-59 years were, respectively, $50,60,70,80$, and $90 \mathrm{mg} / \mathrm{dl}(4)$. Unusual causes for acquired hypobetalipoproteinemia (1-3) such as hyperthyroidism, hepatic necrosis, severe anemia, acute 
trauma, fat malabsorption, and myeloma anti-beta-antibodies were excluded in kindred members.

\section{STUDY PROTOCOL}

After recognizing that neonates with cord blood C-LDL $\leq$ the 2.5 th percentile might have familial hypobetalipoproteinemia (7), we focused on this area of the C-LDL distribution in 3000 infants, who, with their parents, had previously been sampled (16). Since the initial cord blood lipoprotein survey was concerned with the opposite end of the distribution (the upper 5th percentile for C-LDL for the diagnosis of neonatal familial hyperbetalipoproteinemia (16), we had not prospectively followed any of the 11 kindreds finally selected from the low percentiles.

In 3000 neonates, there are by definition, approximately 75 with C-LDL in the bottom $2.5 \%$ of the distribution. All kindreds with infants whose cord blood C-LDL levels were $\leq 10 \mathrm{mg} / \mathrm{dl}$ (the 2.5th percentile) (7) were sent letters explaining our interest in "low" plasma cholesterol levels at birth and inviting participation with resampling of parents, infants, and where possible, the neonates' grandparents and siblings. Twenty percent of the kindreds (15 families) with a hypobetalipoproteinemic neonate had moved from Cincinnati, and were unavailable for follow-up. In 32 kindreds where antecedent studies (16) had revealed low plasma cholesterol levels among parents of hypobetalipoproteinemic infants, major efforts were expended, thus biasing the data to familial aggregations of hypobetalipoproteinemia. No systematic attempt was made to obtain samples from all kindreds identified by neonates with C-LDL $\leq 10 \mathrm{mg} / \mathrm{dl}$. The number of kindreds eventually found to have familial and neonatal hypobetalipoproteinemia possibly underestimates the prevalence of the trait, as diagnosed at birth.

In two kindreds with adult hypobetalipoproteinemic propositi (5), cord blood samples were available in newborns from familial hypobetalipoproteinemia X normal matings.

All follow-up evaluations were done at the out-patient General Clinical Research Center, with blood in adults and children over age 2 drawn after a 12-hour fast. Infants were allowed fruit juice and dry toast before sampling.

Confirmation of the diagnosis of familial hypobetalipoproteinemia in the kindreds with propositus neonates required the following (7): (1) presence of primary hypobetalipoproteinemia in the neonate, a parent, and a grandparent (three-generation vertical transmission of hypobetalipoproteinemia); (2) persistent hypobetalipoproteinemia on follow-up sampling of the infant.

\section{RESULTS}

\section{NEONATAL HYPOBETALIPOPROTEINEMIA}

Of the approximately 75 potential hypobetalipoproteinemic kindred, 11 were longitudinally studied. The selection process for inclusion into the study required availability of the infant for resampling after birth, was biased toward families with parental hypocholesterolemia, and was not prospective, thus being nonsystematic. Of the 11 kindreds identified by a hypobetalipoproteinemic neonatal propositus, three-generation vertically transmitted familial hypobetalipoproteinemia was documented in 2 . In kindred 1, the subject of a preliminary report (8), the neonate, her father (C-LDL 39), paternal grandmother (C-LDL 50 ), and paternal greatgrandmother (C-LDL 61) had familial hypobetalipoproteinemia (Table 1). Follow-up at age 1.5 years revealed persistent hypobetalipoproteinemia, C-LDL $19 \mathrm{mg} / \mathrm{dl}$ (Table 1). In kindred 2, an adult male with documented familial hypobetalipoproteinemia (2) married a normolipidemic woman, after his initial marriage to a distant relative (also with hypobetalipoproteinemia) had produced one child heterozygous for the trait (C-LDL 37), and two children homozygous for the trait with a-betalipoproteinemia (2). The hypobetalipoproteinemic neonate of his second marriage (Table 1), a half-sib of the older homo- and heterozygotes (2), was one of the 3000 livebirths studied (16). A paternal grandfather had hypobetalipoproteinemia, C-LDL $40 \mathrm{mg} / \mathrm{dl}$ (2). Unexpectedly, at 6 month followup, the infant had normal C-LDL, $96 \mathrm{mg} / \mathrm{dl}$, Table 1.

In kindred 7 the infant's mother had low normal C-LDL, 65 $\mathrm{mg} / \mathrm{dl}$, just above the age-specific cutpoint of $60 \mathrm{mg} / \mathrm{dl} \mathrm{(4).}$ There were no living siblings or maternal first degree relatives, and familial hypobetalipoproteinemia was suspected, but could not be confirmed. At age 2 years, the propositus infant retained low levels of C-LDL, $32 \mathrm{mg} / \mathrm{dl}$ (Table 1).

Familial hypobetalipoproteinemia was not demonstrated in any of the remaining eight kindreds with a hypobetalipoproteinemic neonatal propositus. In four kindreds (kindreds 8, 9, 10, and 11), parental C-LDL levels were normal and C-LDL levels in the infants at follow-up were normal $(83,100,90$, and 77 $\mathrm{mg} / \mathrm{dl}$, Table 1). In three kindreds (kindreds 4,5 , and 6), one parent had primary hypobetalipoproteinemia, with C-LDLs of 63,43 , and $55 \mathrm{mg} / \mathrm{dl}$ (Table 1). No other family members in these three kindreds had primary hypobetalipoproteinemia, and C-LDL at follow-up in the three infants was normal $(89,93,96$ $\mathrm{mg} / \mathrm{dl}$, Table 1).

In kindred 3, family studies revealed four-generation vertical transmission of familial hyperalphalipoproteinemia (6). The infant's C-LDL on follow-up was normal, $79 \mathrm{mg} / \mathrm{dl}$, whereas her $\mathrm{C}$-HDL was distinctively elevated at $101 \mathrm{mg} / \mathrm{dl}$ (Table 1 ).

\section{PARENTAL HYPOBETALIPOPROTEINEMIA}

Two kindreds were studied with well defined familial hypobetalipoproteinemia (kindreds 12 and 13, Table 1) (5). Two neonates born to a mating of familial hypobeta-X-normal had normal cord blood cholesterol and C-LDL, with normal cholesterol and C-LDL in later infancy (Table 1).

\section{CLINICAL STUDIES}

When repeat blood samples were obtained from the 11 hypobetalipoproteinemic propositus infants, physical and gross neurologic examinations were normal, as were growth and developmental milestones.

\section{DISCUSSION}

Neonatal and familial hypobetalipoproteinemia (8) was diagnosed in one kindred by quantitation of cord blood C-LDL, four-generation vertical transmission, and by demonstration of persistent hypobetalipoproteinemia in later infancy. In a second kindred, the neonate and her father, grandfather, and halfsiblings had hypobetalipoproteinemia, but the infant's C-LDL was normal, $96 \mathrm{mg} / \mathrm{dl}$, at age 6 months. Whether this unexpectedly normal C-LDL will persist, with a resultant "false positive" diagnosis at birth, can only be determined by longitudinal studies. In a third kindred the hypobetalipoproteinemic neonate retained low C-LDL at age 2 years. Her mother had borderlinelow C-LDL levels, but there were no living siblings or maternal first degree relatives, and familial hypobetalipoproteinemia could not be confirmed. The remaining eight hypobetalipoproteinemic neonates had normal C-LDL on follow-up examination; kindred studies failed to reveal familial hypobetalipoproteinemia. Similar to the report by Naito and Lewis (12), two neonates with normal cord blood C-LDL born to hypobetalipoproteinemic parents retained normal C-LDL levels in infancy.

The 2.5th percentile for C-LDL, $10 \mathrm{mg} / \mathrm{dl}(15)$, used to identify neonatal hypobetalipoproteinemia, was comparable to $12 \mathrm{mg} / \mathrm{dl}$ for 117 neonates (6) and $14 \mathrm{mg} / \mathrm{dl}$ for 494 neonates (13).

Although this study did not systematically include all kindreds from the 3,000 kindred cohort (16) with neonatal C-LDL $\leq 10$ $\mathrm{mg} / \mathrm{dl}$, an estimated prevalence of familial hypobetalipoprotenemia would appear to be 1 in 3000 , with the caveat that with 
Table 1. Neonatal and parental hypobetalipoproteinemia ${ }^{1}(H \beta-L P)$

\begin{tabular}{|c|c|c|c|c|c|c|c|c|c|c|c|c|c|c|c|c|c|}
\hline \multirow{3}{*}{$\begin{array}{c}\text { Kin } \\
\text { dred }\end{array}$} & \multicolumn{6}{|c|}{ Parental } & \multicolumn{4}{|c|}{ Cord blood } & \multicolumn{6}{|c|}{ Follow-up } & \multirow[b]{2}{*}{ Comment } \\
\hline & Sex & Age & Chol & C-HDL & C-LDL & TG & Chol & C-HDL & C-LDL & TG & Sex & Age & Chol & C-HDL & C-LDL & TG & \\
\hline & \multicolumn{6}{|c|}{$\mathrm{H} \beta$-LP parent } & \multicolumn{4}{|c|}{$\mathrm{H} \beta$-LP neonate } & \multicolumn{6}{|c|}{$\mathrm{H} \beta$-LP infant } & \\
\hline \multirow[t]{2}{*}{1} & M & 23 & 117 & 74 & 39 & 10 & 53 & 37 & 9 & 34 & $\mathrm{~F}$ & 1.5 & 85 & 57 & 19 & 43 & $\begin{array}{l}\text { Neonatal and familial } \\
\mathrm{H} \beta-\mathrm{LP}\end{array}$ \\
\hline & & & & & & & & & & & \multicolumn{6}{|c|}{ Normolipidemic infant } & \\
\hline 2 & M & 31 & 72 & 44 & 22 & 32 & 64 & 54 & 2 & 40 & $\mathrm{~F}$ & 0.5 & 133 & 29 & 96 & 40 & $\begin{array}{l}\mathrm{H} \beta \text {-LP at birth, normal } \\
\text { at follow-up. Familial } \\
\mathrm{H} \beta \text {-LP documented } \\
\text { (grandparent, half- } \\
\text { siblings) }\end{array}$ \\
\hline 4 & $\mathrm{M}$ & 30 & 123 & 48 & 63 & 59 & 52 & 37 & 9 & 28 & $\mathrm{M}$ & 2.5 & 160 & 69 & 89 & 10 & $\mathrm{H} \beta$-LP at birth, normal \\
\hline 5 & M & 32 & 116 & 58 & 43 & 74 & 52 & 37 & 10 & 24 & $\mathrm{~F}$ & 2 & 147 & 52 & 93 & 10 & at follow-up. Familial \\
\hline \multirow[t]{2}{*}{6} & $\mathrm{~F}$ & 28 & 133 & 63 & 55 & 64 & 34 & 20 & 8 & 31 & $\mathrm{~F}$ & 0.5 & 150 & 96 & 41 & 70 & $\begin{array}{l}\text { H } \beta \text {-LP not docu- } \\
\text { mented, but parental } \\
\text { H } \beta \text {-LP present. }\end{array}$ \\
\hline & \multicolumn{6}{|c|}{ Parent with low-normal C-LDL } & \multicolumn{4}{|c|}{$\mathrm{H} \beta$-LP neonate } & \multicolumn{6}{|c|}{$\mathrm{H} \beta$-LP infant } & \\
\hline \multirow[t]{2}{*}{7} & $\mathrm{~F}$ & 22 & 154 & 70 & 65 & 98 & 43 & 28 & 8 & 35 & $\mathrm{~F}$ & 2 & 64 & 28 & 32 & 22 & $\begin{array}{l}\mathrm{H} \beta-\mathrm{LP} \text { at birth, and at } \\
\text { age } 2 \text {. Familial } \mathrm{H} \beta- \\
\mathrm{LP} \text { not documented. }\end{array}$ \\
\hline & \multicolumn{6}{|c|}{ Hyper- $\alpha$-LP parent } & \multicolumn{4}{|c|}{ Hyper- $\alpha$-LP, H $\beta$-LP neonate } & \multicolumn{6}{|c|}{ Hyper- $\alpha$-LP infant } & \\
\hline \multirow[t]{2}{*}{3} & $\mathrm{~F}$ & 24 & 237 & 110 & 113 & 68 & 65 & 52 & 9 & 19 & $\mathrm{~F}$ & 0.8 & 188 & 101 & 79 & 43 & $\begin{array}{l}\mathrm{H} \beta \text {-LP at birth. Famil- } \\
\text { ial hyper- } \alpha \text {-LP docu- } \\
\text { mented. }\end{array}$ \\
\hline & \multicolumn{6}{|c|}{ Normolipidemic parents } & \multicolumn{4}{|c|}{$\mathrm{H} \beta$-LP neonate } & \multicolumn{6}{|c|}{ Normolipidemic infant } & \\
\hline \multirow[t]{2}{*}{8} & $\mathrm{~F}$ & 27 & 182 & 59 & 118 & 26 & 64 & 55 & 4 & 23 & $\mathrm{~F}$ & 2 & 145 & 56 & 83 & 32 & $\mathrm{H} \beta$-LP at birth oniy. \\
\hline & $\mathrm{M}$ & 26 & 197 & 46 & 147 & 23 & & & & & & & & & & & \\
\hline \multirow[t]{2}{*}{9} & F & 27 & 189 & 51 & 127 & 55 & 30 & 19 & 6 & 23 & $\mathrm{~F}$ & 3 & 154 & 50 & 100 & 22 & \\
\hline & M & 28 & 243 & 48 & 168 & 134 & & & & & & & & & & & \\
\hline 10 & $\mathrm{~F}$ & 32 & 155 & 69 & 82 & 18 & 53 & 43 & 10 & 30 & $\mathrm{M}$ & 2 & 145 & 45 & 90 & 51 & \\
\hline \multirow[t]{3}{*}{11} & $\mathrm{~F}$ & 26 & 168 & 35 & 112 & 105 & 41 & 24 & 10 & 32 & M & 2 & 130 & 43 & 77 & 52 & \\
\hline & M & 28 & 148 & 46 & 81 & 115 & & & & & & & & & & & \\
\hline & \multicolumn{6}{|c|}{$\mathrm{H} \beta$-LP parent } & Nor & rmolipide & aic neona & & \multicolumn{6}{|c|}{ Normolipidemic infant } & \\
\hline 12 & M & 26 & 101 & 50 & 36 & 74 & 66 & 22 & 35 & 44 & M & 3 & 170 & 47 & 121 & 10 & Normolipidemic off- \\
\hline 13 & M & 32 & 97 & 56 & 20 & 125 & 63 & 32 & 26 & 26 & $M$ & .5 & 134 & 44 & 74 & 202 & $\begin{array}{l}\text { spring of } \mathrm{H} \beta \text {-LP par- } \\
\text { ents. }\end{array}$ \\
\hline
\end{tabular}

${ }^{1}$ Chol: cholesterol; TG: triglycerides; hyper- $\alpha$-LP: hyperalphalipoproteinemia.

so few kindreds identified, chance findings could lead to the prevalence being overestimated. The genetic dyslipoproteinemia is then considerably more common than previously suspected (3). In a previous lipid sampling study of 1200 high school students, three kindreds with familial hypobetalipoproteinemia were identified (2), providing a prevalence estimate of 1 in 400. Stein (13) found one neonate and kindred with familial hypobetalipoproteinemia in a study of 494 neonates.

Cord blood and kindred lipoprotein studies may identify families having heritable "anti-coronary risk" factors $(7,8)$. Future studies of cord blood lipids and lipoproteins will allow a prospective systematic study of all hypobetalipoproteinemic neonates and their kindreds with an aim at more exact delineation of prevalence and "natural history" during infancy and childhood.

\section{REFERENCES AND NOTES}

1. Aggerbeck, L. P., McMahon, J. P., and Scanu, A.: Hypobeta-lipoproteinemia: clinical and biochemical description of a new kindred with "Fredreich's Ataxia." Neurology, 24: 1051 (1974).

2. Cottrill, C., Glueck, C. J., Leuba, V., Millett, F., Puppione, D., and Brown, W. V.: Familial homozygous hypobeta-lipoprotenemia. Metabolism, 23: 779 (1974).

3. Fredrickson, D. S., Gotto, A. M., and Levy, R. I.: Familial lipoprotein deficiency (A-beta-lipoproteinemia, hypobeta-lipoproteinemia and Tangier disease) In: J. B. Stanbury, J. B. Wyngaarden, and D. S. Fredrickson: The Metabolic Basis of Inherited Disease, p. 493 (McGraw Hill, New York, 1972).
4. Fredrickson, D. S., and Levy, R. I.: Familial hyperlipoproteinemia. In: J. B. Stanbury, J. B. Wyngaarden, D. S. Fredrickson: The Metabolic Basis of Inherited Disease, p. 546 (McGraw Hill, New York, 1972).

5. Glueck, C. J., Gartside, P., Fallat, R. W., Sielski, J., and Steiner, P. M.: Longevity syndromes: Familial hypobeta and familial hyperalphalipoproteinemia. J. Lab. Clin. Med., 88: 941 (1976).

6. Glueck, C. J., Gartside, P. S., Tsang, R. C., Mellies, M., and Steiner, P. M.: Black-white similarities in cord blood lipids and lipoproteins. Metabolism, 26: 347 (1977)

7. Glueck, C. J., Gartside, P. M., Tsang, R. C., Mellies, M. J., and Steiner, P. M.: Neonatal familial hyperalphalipoproteinemia. Metabolism, 26: 469 (1977)

8. Glueck, C. J., Tsang, R. C., Mellies, M. J., Fallat, R. W., and Steiner, P. M.: Neonatal familial hypobetalipoproteinemia. Metabolism, 25: 611 (1976).

9. Kwiterovich, P O Levy, R. I and Fredrickson, D S : Neonatal diagnosis of familial type II hyperlipoproteinemia. Lancet, $i: 118$ (1973).

10. Lipid Research Clinics Program, Manual of Laboratory Operations, Vol. 1 (U. S. Government Printing Office, Washington, D. C. 1974).

11. Mars, H., Lewis, L. A., Robertson, L. A., Jr., Butkus, A., and Williams, G. H., Jr.: Familial hypobeta-lipoproteinemia: A genetic disorder of lipid metabolism with nervous system involvement. Amer. J. Med., 46: 886 (1969).

12. Naito, H. K., and Lewis, L. A.: Serum lipoproteins and lipids of familial hyper-, hypo-, or normo-beta-lipoproteinemic subjects during pregnancy. Clin. Chem., 21: 990 (1975).

13. Stein, E. A.: Familial hypobetalipoproteinemia; a family detected by cord blood screening. Amer. J. Dis. Child., 131: 1363 (1977)

14. Stone, N. J., Levy, R. I., Fredrickson, D. S., and Verter, J.: Coronary artery disease in 116 kindred with familial type II hyperlipoproteinemia. Circulation, 49: 476 (1974).

15. Tsang, R., Fallat, R., and Glueck, C. J.: Cholesterol at birth and age one: comparison of normal and hypercholesterolemic neonates. Pediatrics, 53: 458 (1974). 
16. Tsang, R. C., Glueck, C. J., Fallat, R. W., and Mellies, M.: Neonatal familial hypercholesterolemia. Amer. J. Dis. Child., 129: 83 (1975).

17. This research was supported in part by the General Clinical Research Center Grant RR 00068-14, and a portion of this work was done during Dr. Glueck's tenure as an Established Investigator of the American Heart Association, 1971-1976.

18. Signed informed consent was obtained from parents and other kindred

Copyright (c) 1978 International Pediatric Research Foundation, Inc. $0031-3998 / 78 / 1205-0665 \$ 02.00 / 0$ members and the research protocol was approved by the institutional Faculty Community on Human Research.

19. Requests for reprints should be addressed to: Dr. Charles J. Glueck, University of Cincinnati, General Clinical Research Center, Cincinnati General Hospital, 234 Goodman Street, Cincinnati, OH 45267 (USA).

20. Received for publication November 15, 1976 .

21. Accepted for publication August 3, 1977.

Printed in U.S.A. 